\title{
Prospects of 4H-SiC Double Drift Region IMPATT Device as a Photo-Sensitive High-Power Source at 0.7 Terahertz Frequency Regime
}

\author{
Moumita Mukherjee, ${ }^{1}$ Nilratan Mazumder, ${ }^{2}$ and Sitesh Kumar Roy ${ }^{3}$ \\ ${ }^{1}$ Centre of Advanced Study in Radiophysics and Electronics, University of Calcutta 1, Girish Vidyaratna Lane, Kolkata 700009, India \\ ${ }^{2}$ International Institute of Information Technology, Visva Bharati University, X-1, 8/3, Block-EP, Sector V, \\ Salt Lake Electronics Complex, Kolkata 700091, India \\ ${ }^{3}$ Centre of Millimeterwave Semiconductor Devices and Systems, Centre of Advanced Study in Radiophysics and Electronics, \\ University of Calcutta 1, Girish Vidyaratna Lane, Kolkata 700009, India
}

Correspondence should be addressed to Moumita Mukherjee, mou_mita_m@yahoo.com

Received 4 December 2007; Accepted 14 March 2008

Recommended by Tibor Berceli

The dynamic performance of wide-bandgap $4 \mathrm{H}-\mathrm{SiC}$ based double drift region $\left(p^{++} p n n^{++}\right)$IMPATT diode is simulated for the first time at terahertz frequency ( 0.7 Terahertz) region. The simulation experiment establishes the potential of SiC based IMPATT diode as a high power $\left(2.5 \times 10^{11} \mathrm{Wm}^{-2}\right)$ terahertz source. The parasitic series resistance in the device is found to reduce the RF power output by $10.7 \%$. The effects of external radiation on the simulated diode are also studied. It is found that (i) the negative conductance and (ii) the negative resistance of the diode decrease, while, the frequency of operation and the quality factor shift upward under photoillumination. Holes in $4 \mathrm{H}-\mathrm{SiC}$ based IMPATT are found to dominate the modulation activities. The inequality in the magnitude of electron and hole ionization rates in the semiconductors may be correlated with these findings.

Copyright (c) 2008 Moumita Mukherjee et al. This is an open access article distributed under the Creative Commons Attribution License, which permits unrestricted use, distribution, and reproduction in any medium, provided the original work is properly cited.

\section{INTRODUCTION}

Terahertz (THz) science and technology are rapidly developing all over the world. There is strong interest in the exploitation of the $\mathrm{THz}$ frequency range in virtually all fields of basic natural science (physics, chemistry, and biology) as well as medicine [1]. Terahertz applications and technologies for operation in the range between $300 \mathrm{GHz}$ to $10 \mathrm{THz}$ ( 1 millimeter to 30 micrometers) are attracting increased interest from military and security fields. Scientists all over the world are searching for high-power solid-state sources that can be employed as efficient $\mathrm{THz}$ source. Impact avalanche transit time (IMPATT) diodes are the most powerful solid-state sources at $\mathrm{mm}$ and sub-mm-wave frequencies and are widely used in various civilian and space communication systems as well as in high-power radars, missile seekers, and so forth. The conventional IMPATT diodes fabricated on gallium arsenide (GaAs) and silicon (Si) are found to be reliable, but these are limited by power and operating frequencies due to the fundamental limitations of the material parameters. To meet the gradual demand of high-power $\mathrm{THz}$ solid-state sources, extensive research is being carried out for development of highpower (Watt level) IMPATT devices that can be operated at high-frequency region. One approach is to employ power combining technique to increase the output power of the IMPATT devices, but it is practically difficult to combine large number of devices. The other option is to develop IMPATT devices from wide bandgap (WBG) semiconductors having high-critical electric field $\left(E_{C}\right)$ and high-thermal conductivity $(K)$ [2]. High value of $E_{C}$ as well as highsaturation drift velocity of charge carriers $\left(v_{s n, s p}\right)$, is essential criterion for selecting suitable base semiconductor material for IMPATT fabrication, since the RF power density $\left(P_{\mathrm{RF}}\right)$ of an IMPATT device is proportional to $E_{c}^{2} \cdot v_{s}^{2}$. Moreover, to achieve good thermal stability in $\mathrm{THz}$ devices, the base material should have high value of thermal conductivity $(K)$ also. Considering all these facts, WBG semiconductor silicon carbide $(\mathrm{SiC})$ is an automatic choice for designing of high-power IMPATT, because this material offers at least 
(i) $10 \times E_{c}$, (ii) $1.5 \times v_{s}$, and (iii) $3 \times K$, in comparison to those of conventional Si, GaAs, and indium phosphide (InP). That means, SiC IMPATTs are likely to produce $400 \times P_{\mathrm{RF}}$ than its counterparts. The expected excellent performances of WBG SiC-based devices can be assessed by figures of merit (FOM). Keyes' FOM considers the speed of transistors and their thermal limitation, and Johnson's FOM considers the high-frequency and high-power capability of devices. Taking Keyes' and Johnson's FOM for Si as unity, the Keyes' and Johnson's FOM for GaAs are 0.45 and 7.1, respectively, while those of $4 \mathrm{H}-\mathrm{SiC}$ are 5.1 and 278 [2]. Following the FOMs for high-frequency and high-temperature operation $\mathrm{SiC}$ is found to be superior to both $\mathrm{Si}$ and GaAs. The availability of $4 \mathrm{H}-\mathrm{SiC}$ polytypes in bulk wafer form [3, 4] has helped $\mathrm{SiC}$ to emerge as relatively mature wide bandgap semiconductor technologies. So, in the light of the maturity of the fabrication technology and the unique material parameters, WBG semiconductors, especially, SiC appear to be the best choice, overall, for the next decade of device development particularly at $\mathrm{THz}$ region. At lowfrequency region, the superiority of $4 \mathrm{H}$-SiC-based IMPATT over the traditional IMPATTs is already reported [5]. But the prospects of $\mathrm{SiC}$ as high-power $\mathrm{THz}$ source are still not explored. The authors in this paper have reported for the first time the potential of $4 \mathrm{H}-\mathrm{SiC}$ as a suitable base material for $\mathrm{THz}$ IMPATT device. Presently, two SiC polytypes are popular in SiC research: $6 \mathrm{H}-\mathrm{SiC}$ and $4 \mathrm{H}-\mathrm{SiC}$. Although both the polytypes have similar properties, $4 \mathrm{H}-\mathrm{SiC}$ is preferred over $6 \mathrm{H}-\mathrm{SiC}$ because the carrier mobilities in $4 \mathrm{H}-\mathrm{SiC}$ are isotropic, that is, identical along the two planes (parallel and perpendicular to $c$-axis) of the hexagonal semiconductor, whereas in $6 \mathrm{H}-\mathrm{SiC}$, carriers exhibit anisotropic mobility. Moreover, it is already reported that the high-frequency performance of $4 \mathrm{H}-\mathrm{SiC}$ IMPATT is far better than its $6 \mathrm{H}$ SiC counterpart in terms of $V_{B}$ as well as $P_{\mathrm{RF}}$ [6]. Thus, the possibility of generating high power from an IMPATT has been investigated by studying the DC and small-signal properties of WBG $4 \mathrm{H}$-SiC-based flat profile DDR (double drift region, $p^{++} p n n^{++}$) IMPATT diode simulated for operation at $\mathrm{THz}$ regime.

Parasitic positive series resistance $\left(R_{S}\right)$ is a crucial parameter that limits power dissipation and causes burn out problem in high frequency IMPATTs. Apart from the contribution from substrate, the $\mathrm{p}-\mathrm{n}$ junction diode parameters, especially, the width of the depletion layer, doping density, and so forth, also contribute to $R_{S}$. Moreover, the contact resistance of the device contributes significantly to the total parasitic series resistance. The authors have determined the value of $R_{S}$ of the simulated IMPATT device considering contribution from the substrates, undepleted epitaxial layer and ohmic contacts. The authors have evaluated the values of $R_{S}$ for the designed diode through a generalized simulation technique, and its effect on exploitable power level of the device has also been simulated.

Optical control of the dynamic properties of $\mathrm{THz}$ IMPATT device can have tremendous application in advanced radars and space communication systems. Basic process involved is that, when a photon (due to optical /other radiation) of energy $\mathrm{h} v$ greater than the bandgap of the semiconductor is absorbed at the edges of the reversed biased $\mathrm{p}-\mathrm{n}$ junction of an IMPATT diode, creation of additional electron-hole pairs takes place within the active region of the diode. These photogenerated carriers give rise to photocurrent and thereby enhance the existing thermal leakage current in the IMPATT diode. The enhanced leakage current alters the avalanche phase delay in the diode, which subsequently modifies the phase and magnitude of terminal current in the device oscillator circuit. The previous experimental [7] as well as theoretical $[5,6]$ studies on optically illuminated IMPATT diodes indicated that the photogenerated carriers reduce the efficiency and power output of the devices, but increase the tuning range of the devices in the mm-wave frequency band. Moreover, a recent report on the effect of ionizing radiation on Si IMPATT diode characteristics establishes that control of IMPATT performance by any external radiation is an emerging technique that is currently being explored for important application possibilities [8]. These interesting results for photoilluminated IMPATTs have prompted the authors to investigate theoretically the role of external radiation in modulating the dynamic properties of the $4 \mathrm{H}-\mathrm{SiC}$ DDR THz IMPATT. A modified simulation scheme has been used for this purpose.

\section{THEORY OF SIMULATION TECHNIQUE}

The simulation method consists of three parts: (i) dc analysis, (ii) small-signal analysis, and (iii) simulation technique for studying illumination effect. The IMPATT diode is basically a $\mathrm{p}-\mathrm{n}$ junction diode that operates when it is reverse-biased to avalanche breakdown condition. A one-dimensional model of the $\mathrm{p}-\mathrm{n}$ junction has been considered in the present analysis. The following assumptions have been made in the simulation of $\mathrm{dc}$ and small-signal behavior of $4 \mathrm{H}-\mathrm{SiC} \mathrm{DDR}$ IMPATT diodes: (i) the electron and hole velocities have been taken to be saturated and independent of the electric field throughout the space charge layer, (ii) the effect of carrier space-charge has been considered, and (iii) the effect of carrier diffusion has been neglected.

$4 \mathrm{H}-\mathrm{SiC}$ DDR diode is first designed and optimized through a generalized double iterative simulation technique used for analysis of IMPATT action [9]. The method involves iteration over the magnitude of field maximum $\left(E_{m}\right)$ and its location in the depletion layer. The electric field and carrier current profiles are obtained through simultaneous solution of Poisson and current continuity equations. The experimental values of material parameters, namely, realistic field dependence of ionization rates, saturated drift velocities, and mobility of charge carriers in $4 \mathrm{H}-\mathrm{SiC}[10]$ are incorporated in the present analysis. The junction temperature is assumed to be $300 \mathrm{~K}$. The device dimensions, doping, and current densities of the diode (shown in Table 1) are optimized for operation at around $700 \mathrm{GHz}$ after several computer runs.

The small-signal analysis of the IMPATT diode is carried out through a double iterative simulation technique [9], used to solve two second-order differential equations involving diode resistance $\left(Z_{R}\right)$ and reactance $\left(Z_{X}\right)$. The small-signal admittance characteristics (negative conductance $(-G)$ 
TABLe 1: Design parameters of $4 \mathrm{H}-\mathrm{SiC}$ impatt at thz frequency.

\begin{tabular}{lccccc}
\hline $\begin{array}{l}\text { DDR } \\
\text { diode type }\end{array}$ & $\begin{array}{l}\text { Doping conc. }(n \\
\text { region })\left(10^{24} \mathrm{~m}^{-3}\right)\end{array}$ & $\begin{array}{l}\text { Doping conc. }(p \\
\text { region })\left(10^{23} \mathrm{~m}^{-3}\right)\end{array}$ & $\begin{array}{l}\text { Width of the } n \\
\text { region }(\mathrm{nm})\end{array}$ & $\begin{array}{l}\text { Width of the } p \\
\text { region }(\mathrm{nm})\end{array}$ & $\begin{array}{l}\text { Current density } \\
\left(10^{10} \mathrm{~A} \mathrm{~m}^{-2}\right)\end{array}$ \\
\hline 4H-SiC & 3.0 & 3.0 & 80.0 & 80.0 & 1.37 \\
\hline
\end{tabular}

versus susceptance $(B)$ plots), device negative resistance, and device quality factor $(Q=B / G)$ of the optimized SiC DDR diode are determined by this technique after satisfying the appropriate boundary conditions [11]. The total integrated negative resistance $\left(Z_{R}\right)$ and reactance $\left(Z_{X}\right)$ of the diodes at a particular frequency $\omega$ can be determined from the numerical integration of the resistivity $(R)$ and the reactivity $(X)$ profiles over the depletion layer (depletion layer width is $w)$ as follows:

$$
\begin{aligned}
& Z_{R}=\int_{0}^{w} R d x, \\
& Z_{X}=\int_{0}^{w} X d x .
\end{aligned}
$$

Diode impedance is expressed as $Z(x, \omega)=R(x, \omega)+X(x, \omega)$. Moreover, the total diode impedance $Z_{\text {total }}(\omega)$ is obtained by

$$
Z_{\text {total }}(\omega)=\int_{0}^{w} Z(x, \omega) d x=Z_{R}+j Z_{X}
$$

The diode total negative conductance $(G)$ and susceptance $(B)$ have been calculated from the following expressions:

$$
G=-\frac{Z_{R}}{\left(Z_{R}\right)^{2}+\left(Z_{X}\right)^{2}}, \quad B=\frac{Z_{X}}{\left(Z_{R}\right)^{2}+\left(Z_{X}\right)^{2}} .
$$

$G$ and $B$ are function of RF voltage ( $\left.V_{\mathrm{RF}}\right)$ and frequency such that the steady-state condition for oscillation is given by [12]

$$
g(\omega)=-G(\omega)-\{B(\omega)\}^{2} R_{S}(\omega),
$$

where $g$ is load conductance. $G, B$, and $g$ are normalized to the area of the diode. The relation provides minimum uncertainty in $g$ at low-power oscillation threshold. The authors have evaluated $R_{S}$ from the admittance characteristics using the realistic analysis of Gummel and Blue [13], and Alderstein et al. [12] without any drastic assumption. Under the small-signal condition, $V_{\mathrm{RF}}$ (amplitude of the RF swing) has been taken as $V_{B} / 2$, assuming $50 \%$ modulation of the breakdown voltage $V_{B}$. For such a small value of $V_{\mathrm{RF}}, R_{S}$ has been calculated by considering the value of $g$ nearly equal to the diode conductance $(G)$ at resonance. The maximum RF power density $\left(P_{\mathrm{RF}}\right)$ from the device is obtained from the expression:

$$
P_{\mathrm{RF}}=\frac{V_{\mathrm{RF}}^{2} G_{P}}{2}
$$

The diode negative conductance at the optimum frequency $\left(-G_{p}\right)$ is normalized to the area of the diode. The space step for the present simulation technique is set as $\sim 10^{-10} \mathrm{~m}$. The validity of this simulation method was reported earlier for subterahertz and $\mathrm{THz}$ IMPATT diodes $[11,14]$.

The leakage current $\left(J_{s}\right)$, entering the depletion region of the reversed biased $\mathrm{p}-\mathrm{n}$ junction of an IMPATT diode, is normally due to thermally generated electrons and holes $\left[J_{s}=J_{n s(\mathrm{th})}+J_{p s(\mathrm{th})}\right]$, and it is so small that electron and hole current multiplication factor,

$$
M_{n, p}=\frac{J_{0}}{\left[J_{n s(\text { th })} \text { or } J_{p s(\text { th })}\right]}, \quad\left[J_{0}=\text { bias current density }\right]
$$

can be considered to be infinitely large. Thus, the enhancement of the leakage current under optical illumination of the devices is manifested as the lowering of $M n, p$. In a DDR IMPATT structure, the composition of photocurrent may be altered by shining a laser beam selectively on the $p^{++}$or $n^{++}$side of the device through fabricated optical windows of appropriate diameter, keeping the diode mounted in a microwave cavity. Thus, the electron saturation current and also the hole saturation current might be enhanced separately, which would produce changes in the small-signal behavior of SiC-based device. The top mounted (TM) and flip chip (FC) structures, shown in Figure 1, illustrate the optical illumination schemes for generation of electron and hole dominated photocurrents, respectively. In order to assess the role of leakage current in controlling the dynamic properties of $4 \mathrm{H}-\mathrm{SiC}$ IMPATT oscillators, simulation studies are carried out by the authors on the effect of $M_{n}$ (keeping $M_{p}$ very high $\sim 10^{6}$ ) and $M_{p}$ (keeping $M_{n}$ very high $\sim 10^{6}$ ) on (i) the small signal negative conductance, (ii) the RF power, and (iii) device negative resistance $\left(Z_{R P}\right)$ of flat profile $4 \mathrm{H}$ SiC DDR IMPATT. The details of mathematical calculations based on modified boundary conditions due to enhancement of leakage current are described elsewhere [11].

\section{RESULTS AND DISCUSSIONS}

The optimized design parameters of the unilluminated SiC DDR IMPATT diode for which $M_{n}$ and $M_{p}$ are both large $\left(=10^{6}\right)$ are mentioned in the last section. The DC and highfrequency properties of the simulated diode are reported in Table 2 and will be discussed first. Table 2 shows that the THz IMPATT diode based on SiC breaks down at 55.3 V. The simulated diode is capable of generating a maximum $P_{\mathrm{RF}}$ of $2.8 \times 10^{11} \mathrm{Wm}^{-2}$ with efficiency $10.5 \%$.

Table 3 shows the value of $R_{S}$ at $0.7 \mathrm{THz}$ for the simulated diode. The small-signal values of negative conductance $(G)$, susceptance $(B)$, and expected values of load conductance ( $g$, at low-power oscillation threshold) are also reported in Table 3. The value of $\mathrm{R}_{S}$ for $4 \mathrm{H}-\mathrm{SiC}$ IMPATT is found 


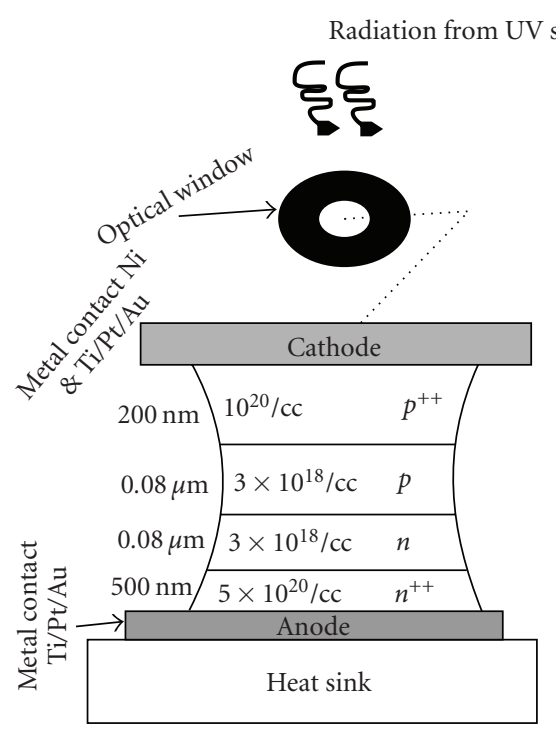

(a)
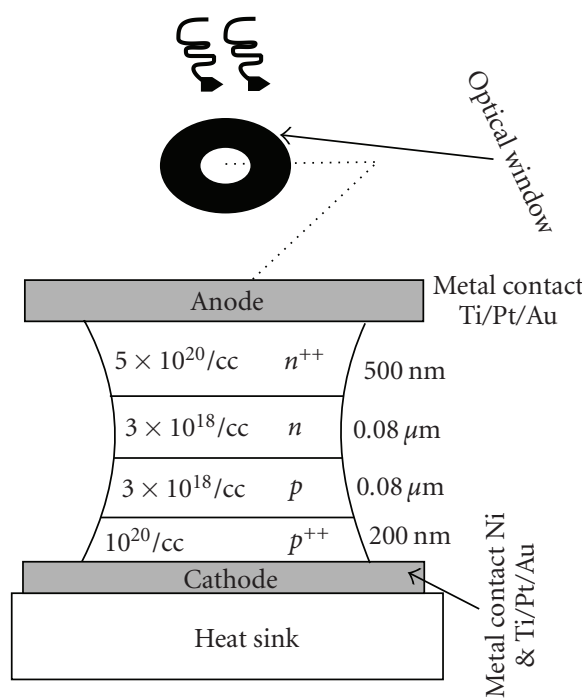

(b)

FIGURE 1: Schematic diagram of (a) top mounted and (b) flip chip DDR IMPATT diode under optical-illumination.

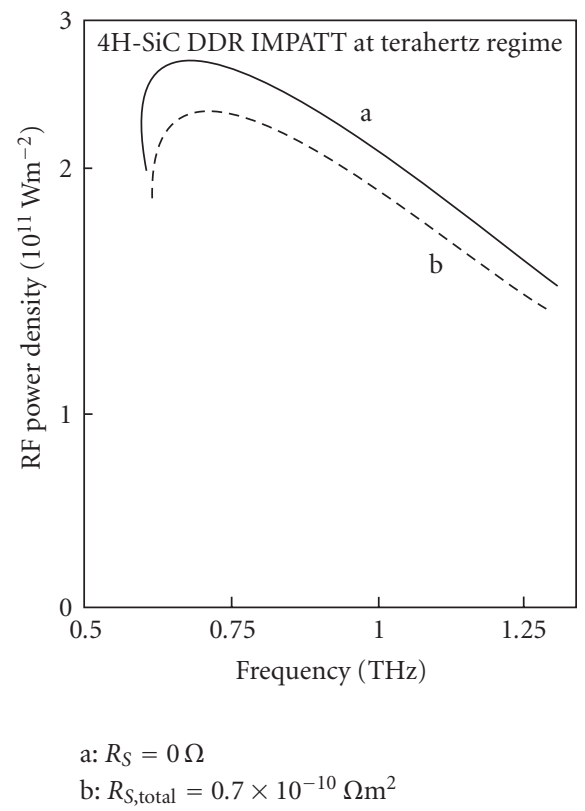

FIGURE 2: Effect of series resistance on RF power density of $4 \mathrm{H}-\mathrm{Sic}$ Terahertz IMPATT diode.

to be $0.49 \times 10^{-10} \Omega \mathrm{m}^{2}$. Ohmic contact resistance may put a severe restriction on the high frequency ( $\mathrm{THz}$ level) performance of the wide bandgap IMPATT devices and thus the presence of contact resistance should be included in the realistic consideration of parasitic positive series resistance. A very recent study showed that ohmic contact to $\mathrm{n}-\mathrm{SiC}$ are formed by using pure Ni-based layer with a thin underlying Si layer. By this technique, a stable and low n-SiC contact resistivity of $\sim 10^{-7} \Omega \mathrm{cm}^{2}$ can be realized in practice [15].

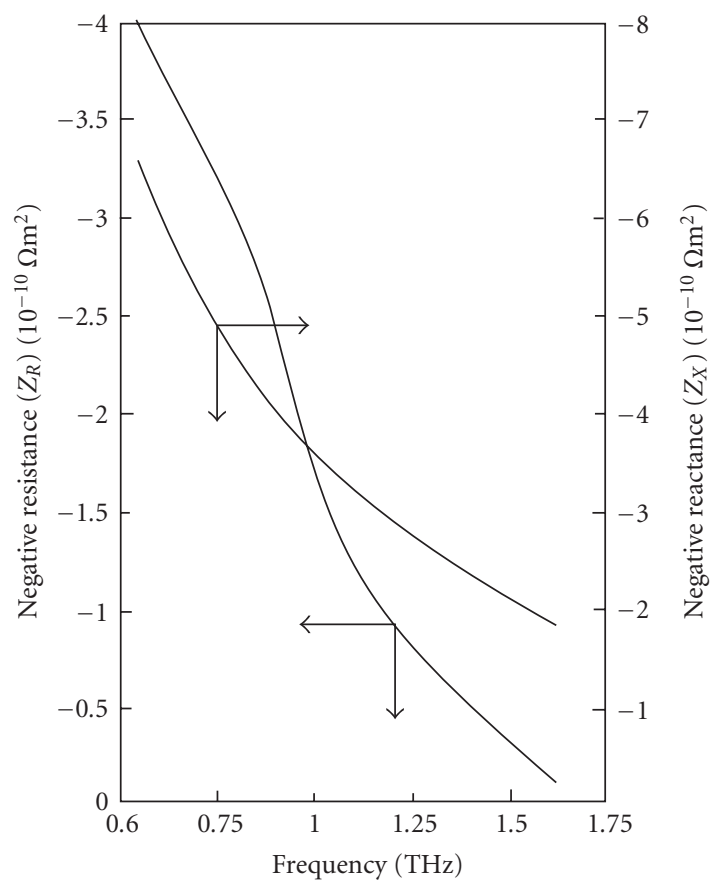

FIgure 3: Impedance plots of 4H-SiC IMPATT diode at Terahertz region.

Very low specific contact resistance for $\mathrm{p}$-SiC has not been achieved in reality. Using alloy composition such as $\mathrm{Ni} / \mathrm{Al}$ to $\mathrm{p}$-SiC, a contact resistivity $\sim 10^{-6} \Omega \mathrm{cm}^{2}$ can be realized in practice [16]. It is noteworthy to mention that, in order to get appreciable power (Watt level) from a $\mathrm{THz}$ source, low specific contact resistance $\left(\sim 10^{-7} \Omega \mathrm{cm}^{2}\right)$ should be achieved, since at $\mathrm{THz}$ region intrinsic diode negative resistance is usually very small. It may be predicted that, further increasing the doping concentration of $\mathrm{p}$-SiC semiconductor 


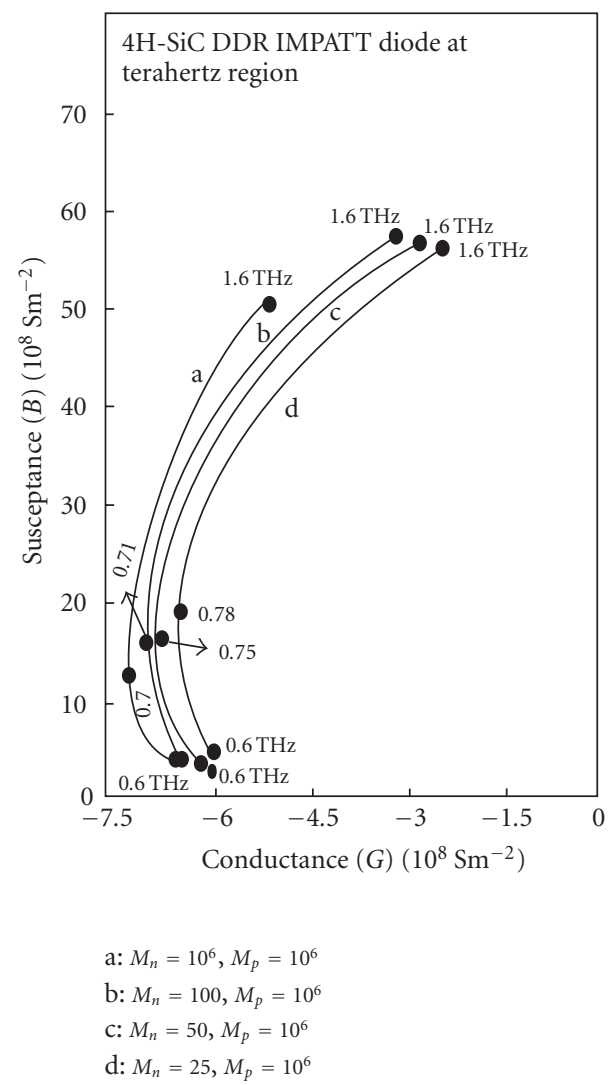

(a)

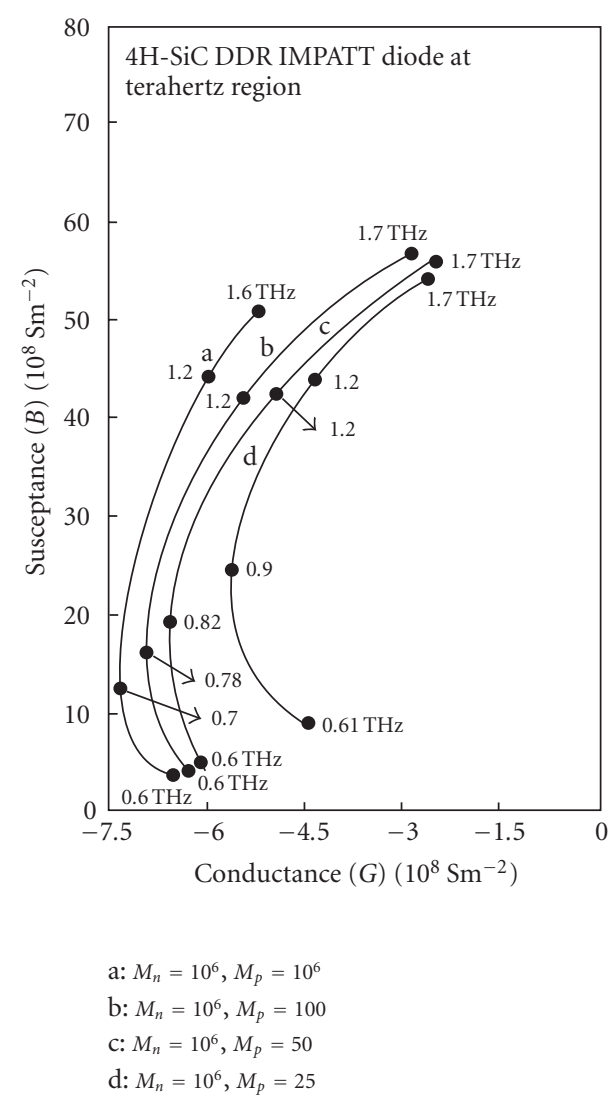

(b)

FIGURE 4: (a) Effect of electron dominated photo-current on 4H-SiC DDR IMPATT diode at terahertz region. (b) Effect of hole dominated photo-current on $4 \mathrm{H}-\mathrm{SiC}$ DDR IMPATT diode at terahertz region.

TABLE 2: Dc and small-signal properties of 4H-SiC IMPATT diode.

\begin{tabular}{lc}
\hline Diode parameters & 4H-SiC DDR IMPATT \\
\hline$E_{m}\left(10^{8} \mathrm{~V} \mathrm{~m}^{-1}\right)$ & 5.25 \\
$V_{B}(\mathrm{~V})$ & 55.3 \\
$\eta(\%)$ & 10.5 \\
$f_{P}(\mathrm{THz})$ & 0.7 \\
$-G_{p}\left(10^{8} \mathrm{~S} \mathrm{~m}^{-2}\right)$ & 7.40 \\
$-Q_{P}$ & 1.6 \\
$P_{\mathrm{RF}}\left(R_{s}=0.0 \Omega\right)\left(10^{11} \mathrm{Wm}^{-2}\right)$ & 2.8 \\
$P_{\mathrm{RF}}\left(R_{s, \text { total }}=0.7 \Omega\right)\left(10^{11} \mathrm{Wm}^{-2}\right)$ & 2.5 \\
\hline
\end{tabular}

material, a desired contact resistivity $\sim 10^{-7} \Omega \mathrm{cm}^{2}$ may be achieved in reality. Hence, more realistic values of effective parasitic series resistance $\left(R_{S \text {,total }}\right.$, including the contribution of contact resistance) become approximately $0.7 \times 10^{-10} \Omega \mathrm{m}^{2}$ for $4 \mathrm{H}-\mathrm{SiC}$ IMPATT. Measurement of such a low contact resistance may be possible with transmission line measurement (TLM) technology. The effect of $R_{S \text {,total }}$ on $P_{\mathrm{RF}}$ of the diode is shown in Figure 2. It is reflected in Figure that even in the presence of aforesaid $R_{S \text {,total }}$ an appreciable RF power density of $2.5 \times 10^{11} \mathrm{Wm}^{-2}$ may be obtained from the simulated $\mathrm{THz}$ device.
Figure 3 shows the small-signal impedance plot for the $\mathrm{THz}$ diode.The graphs show that the device possesses negative resistance for all frequencies above the avalanche frequency $\left(f_{a}\right)$, where its reactance is capacitive. This is due to the fact that, in the oscillating frequency range, the magnitude of $Z_{R}$ is found to be small compared to $Z_{X}$. This is also evident from Figure 3, that the values of $\left|-Z_{R}\right|$ and $\left|-Z_{X}\right|$ decrease as the operating frequency increases.

The effects of electron and hole dominated photocurrents on the THz performance of the WBG IMPATT are presented in Table 4 . The table shows that the values of $\left|-G_{P}\right|$ of the diode decrease with the lowering of $M_{n}$ and $M_{p}$. At the same time, the frequency range over, which the device exhibits negative conductance, shifts towards higher frequencies with the lowering of $M_{n}$ as well as $M_{p}$. The output data for illuminated TM and FC flat DDR IMPATT diodes (see Table 4) indicate that the value of negative conductance at peak frequency $\left|-G_{P}\right|$ decreases by $6.7 \%$ when $M_{n}$ reduces from $10^{6}$ to 25 for SiC-based $\mathrm{THz}$ device, while for the similar lowering of $M_{p},\left|-G_{P}\right|$ decreases by $23.0 \%$. The identical trend is reflected in Figures $4(\mathrm{a})$ and 4(b), where the admittance plots of SiC-based photoilluminated $\mathrm{THz}$ device are plotted. The figures show that the effect of hole dominated photocurrent in modulating the admittance characteristics is much prominent than the 


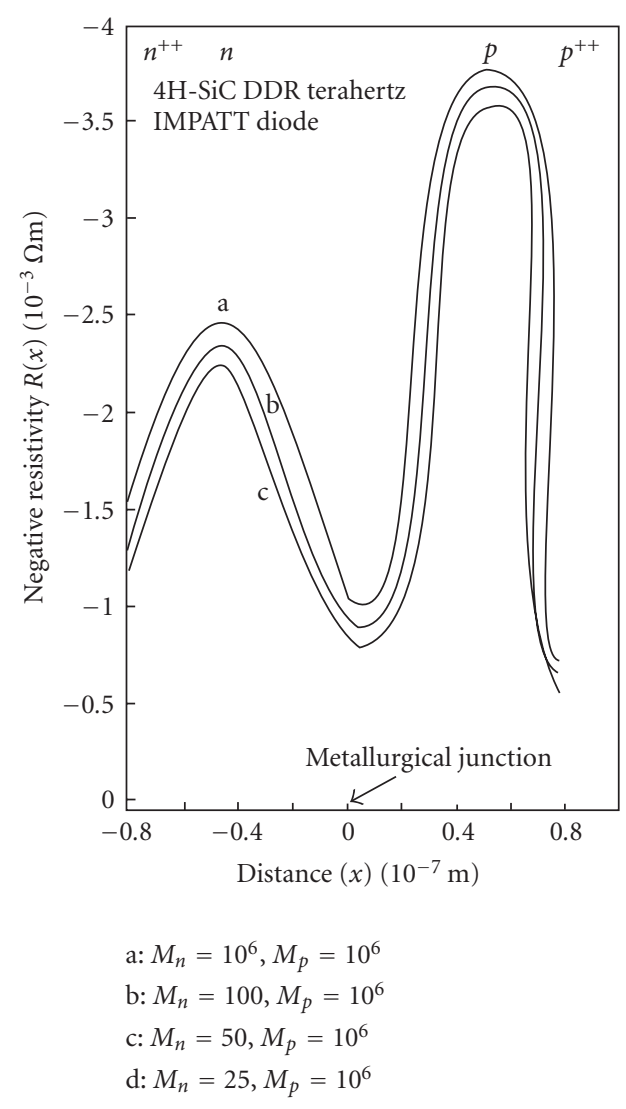

(a)

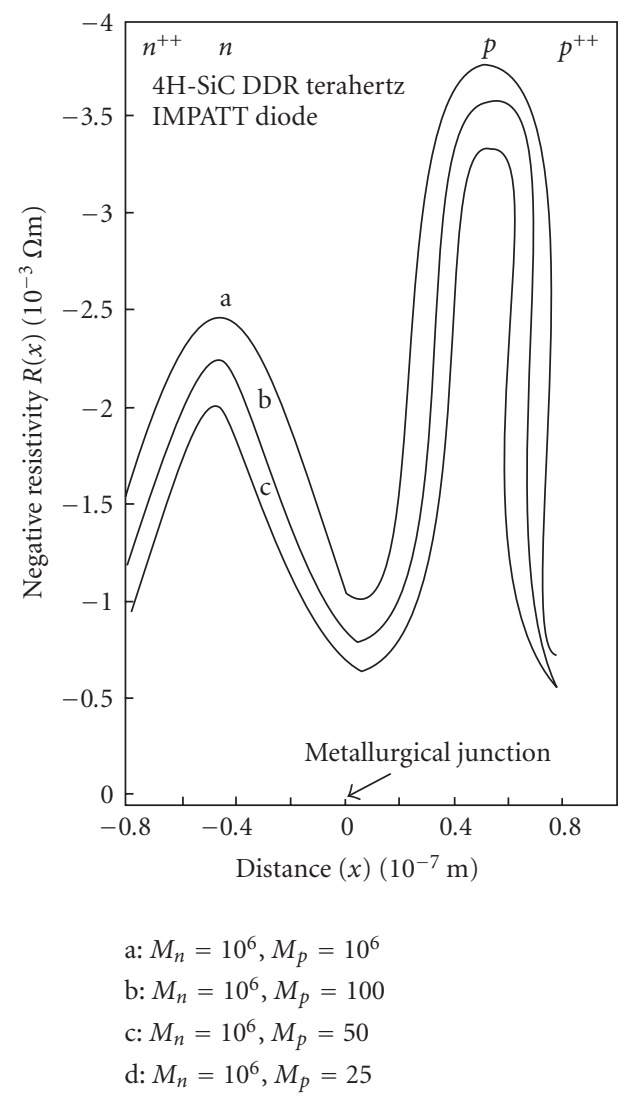

(b)

FIGURE 5: (a) Effect of electron dominated photo-current on negative resistivity profile of 4H-SiC DDR IMPATT diode. (b) Effect of hole dominated photo-current on negative resistivity profile of $4 \mathrm{H}-\mathrm{SiC}$ DDR IMPATT diode.

TABLE 3: Series resistance of 4H-SiC IMPATT at $0.7 \mathrm{THz}$.

\begin{tabular}{lcccc}
\hline $\begin{array}{l}\text { Negative } \\
\text { conductance } \\
(-G)\left(10^{8} \mathrm{Sm}^{-2}\right)\end{array}$ & $\begin{array}{l}\text { Susceptace } \\
(\mathrm{B})\left(10^{8} \mathrm{Sm}^{-2}\right)\end{array}$ & $\begin{array}{l}\text { Load conductance } \\
\left(10^{8} \mathrm{Sm}^{-2}\right)\end{array}$ & $\begin{array}{l}\text { Series resistance } \\
\left(R_{S}\right)\left(10^{-10} \Omega \mathrm{m}^{2}\right)\end{array}$ & $\begin{array}{l}\text { Negative resistance } \\
\left(-Z_{R}\right)\left(10^{-10} \Omega \mathrm{m}^{2}\right)\end{array}$ \\
\hline 7.4 & 12.0 & 6.7 & 0.49 \\
\hline
\end{tabular}

electron dominated photocurrent. The optimum frequency of oscillation $\left(f_{P}\right)$ for the illuminated $\mathrm{SiC}$ diode increases by $11.4 \%$ as $M_{n}$ reduces from $10^{6}$ to 25 . However, for the similar variation of $M_{p}$, the upward shift of $f_{P}$ is much higher (29.0\%).

Figures 5(a) and 5(b) show the profiles of negative resistivity at the peak frequencies corresponding to different values of $M_{n}\left(M_{p}=10^{6}\right)$ and $M_{p}\left(M_{n}=10^{6}\right)$ for SiCbased diode, respectively. Negative resistivity profiles give a physical insight into the region of the depletion layer that contributes to RF power. In each case, the profiles are characterized by two negative resistivity peaks in the middle of the two drift layers of the diode interspaced by a dip in the avalanche region. It is observed from the figures that due to the enhancement of electron and hole photocurrents, the negative resistivity peaks in the electron, and hole drift layers are depressed gradually. It is also found that the decrease in the magnitude of the negative resistivity peaks is more pronounced for variation of $M_{p}$ corresponding to hole dominated photocurrent than for the same variation of $M_{n}$ corresponding to electron dominated photocurrent.

Simulation study also depicts that in case of $4 \mathrm{H}-\mathrm{SiC}$ DDR IMPATT, as $M_{n}$ is decreased from $10^{6}$ to 25 , there occurs a $54.0 \%$ decrease in the diode negative resistance $\left(-Z_{R p}\right)$. On the other hand, as $M_{p}$ changes from $10^{6}$ to $25,-Z_{R p}$ reduces by $74.3 \%$ (see Table 4 ).

The variations of power output with optimum frequency for different values of $M_{n}$ and $M_{p}$ are also shown in Table 4. Again, it is found from the study that the magnitude of device quality factor at optimum frequency of oscillation $\left|-Q_{P}\right|$ increases appreciably for a decrease of $M_{p}$ compared to the same change of $M_{n}$ values (see Table 4 ).

The enhancement of leakage currents by electron and hole dominated photocurrents thus leads to a decrease of 
TABLE 4: Variation of small-signal properties of 4H-SiC DDR IMPATT under optical-illumination.

\begin{tabular}{ccccccc}
\hline$M_{n}$ & $M_{p}$ & $f_{P}(\mathrm{THz})$ & $-G_{p}\left(10^{8} \mathrm{Sm}^{-2}\right)$ & $-Z_{R p}\left(10^{-10} \Omega \mathrm{m}^{2}\right)$ & $P_{\mathrm{RF}}\left(10^{11} \mathrm{Wm}^{-2}\right)$ & 2.82 \\
\hline $10^{6}$ & $10^{6}$ & 0.70 & 7.4 & 3.8 & 2.75 \\
100 & - & 0.71 & 7.2 & 2.6 & 2.6 \\
50 & - & 0.75 & 7.1 & 2.1 & 2.71 \\
25 & - & 0.78 & 6.9 & 1.7 & 2.63 \\
$10^{6}$ & 100 & 0.78 & 7.0 & 2.5 & 2.67 \\
- & 50 & 0.82 & 6.4 & 1.6 & 2.75 \\
- & 25 & 0.90 & 5.7 & 0.95 & 2.45 \\
\hline
\end{tabular}

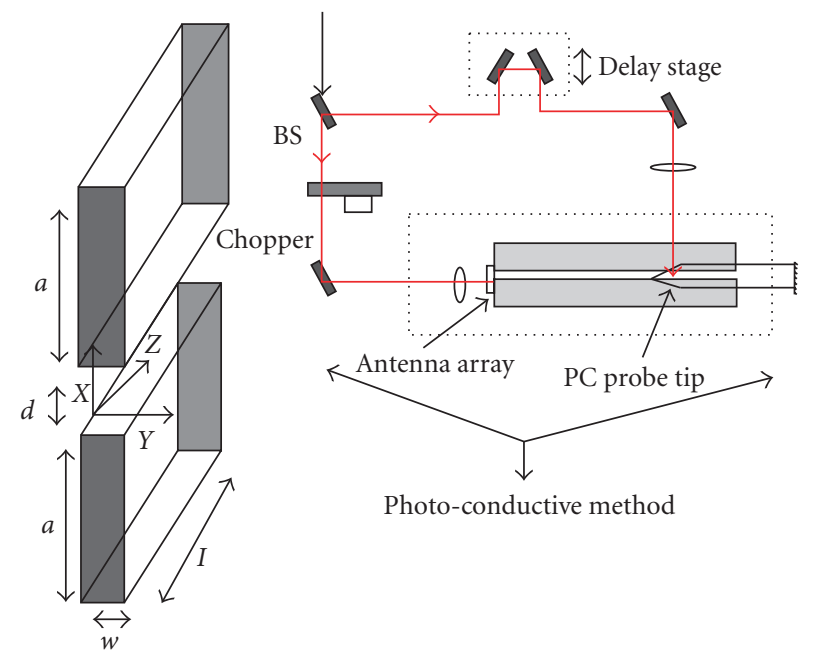

FIGURE 6: Waveguide goemetry: $d=270 \mu \mathrm{m}, w=300.0 \mu \mathrm{m}$, and $l=140.0 \mathrm{~mm}$.

$-Z_{R P},-G_{P}$, and $P_{\mathrm{RF}}$ along with a simultaneous upward shift of $f_{P}$. While the photo-generated leakage current dominated by holes modulates the DC and high-frequency properties of the device appreciably, that dominated by electrons has relatively less effect in modulating the same. For the mmwave Si DDR, it was reported that the electron saturation current was more dominant in changing the $P_{\mathrm{RF}}$ and the $f_{P}$ [7]. In $\mathrm{Si}$, the electron ionization rate is greater than the hole ionization rate. This means that by controlling the DDR IMPATT action through more ionizing carriers in Si, a higher frequency shift may be achieved. By the same logic, it can also be concluded that in $4 \mathrm{H}-\mathrm{SiC}$, holes are more ionizing carriers than electrons, since $4 \mathrm{H}-\mathrm{SiC}$ DDR IMPATT under optical illumination at $\mathrm{THz}$ region is more sensitive to hole dominated photocurrent. This relative predominance of hole leakage current in optical control of $4 \mathrm{H}-\mathrm{SiC} \mathrm{DDR}$ IMPATT performance can be attributed to the inequality of the ionization coefficient values in $4 \mathrm{H}-\mathrm{SiC}[10]$.

The thermal conductivity of $4 \mathrm{H}-\mathrm{SiC}\left(\sim 500 \mathrm{~W} \mathrm{~m}^{-1} \mathrm{~K}^{-1}\right)$ is very high. This helps the SiC IMPATT to dissipate the generated heat quickly from the junction. Moreover, if a diamond heat sink is employed for the practical realization of $4 \mathrm{H}-\mathrm{SiC} \mathrm{THz}$ IMPATT device, the effective thermal conductivity will increase to such a high value that the junction temperature will not increase significantly over the ambient $(300 \mathrm{~K})$, though the device yields a $P_{\mathrm{RF}}$ of $2.5 \times 10^{11} \mathrm{Wm}^{-2}$.
Due to lack of any experimental data on $\mathrm{SiC} \mathrm{THz}$ IMPATT diode, the simulation results could not be compared. However, the nature of variation of $\mathrm{THz}$ properties of the designed diode under photoillumination has a trend agreement with the experimental results of Si-based IMPATT diode at lower frequency region. It may be mentioned here that a large-signal computer simulation may provide improved quantitative information regarding the influence of optical illumination on the frequency tuning as well as RF power output, but the nature of response to optical illumination, as predicted by the small-signal analysis, will remain unchanged.

\section{CONCLUSION}

The current simulation study establishes that $4 \mathrm{H}-\mathrm{SiC}$-based DDR IMPATT diode can generate high power even at a frequency as high as $0.7 \mathrm{THz}$. In the earlier reported paper [14], the frequency of operation was limited to $0.5 \mathrm{THz}$ only. Moreover, in the present paper, the authors have realistically simulated the value of total parasitic series resistance for $\mathrm{THz}$ SiC IMPATT, which includes the contribution both from the diode as well as from ohmic contact resistance, while, in the previous article [14], the series resistance due to contact metals was not considered. Based on the information of total series resistance, provided in this paper, one can get more accurate idea of exploitable power level from the SiC DDR diode at $\mathrm{THz}$ region. Further, the effect of external radiation on this device at $0.7 \mathrm{THz}$ seems to be significantly prominent. It is thus expected that the photo-irradiated $4 \mathrm{H}$ SiC DDR IMPATT at still higher frequencies will have better frequency tuning capability. A discussion on feasibility of experimental validation was not incorporated in the previous article [14]. In the present paper, the authors will discuss below the possibility of experimental verification of optical illumination on the $4 \mathrm{H}-\mathrm{SiC}$ DDR diode. The realization of $4 \mathrm{H}-\mathrm{SiC} \mathrm{THz}$ IMPATT diode may be done through the following process steps.

Device fabrication following usual process steps like photolithography, deposition of metal contacts, and mesa formation by reactive ion etching.

Characterization of $\mathrm{THz}$ properties may be possible with a dielectric coplanar wave guide, the device being an integral part of the waveguide.

For terahertz $(0.1-1 \mathrm{THz})$ power transmission, a metallic slit waveguide, fabricated by sawing a $270 \mu \mathrm{m}$ wide slit 


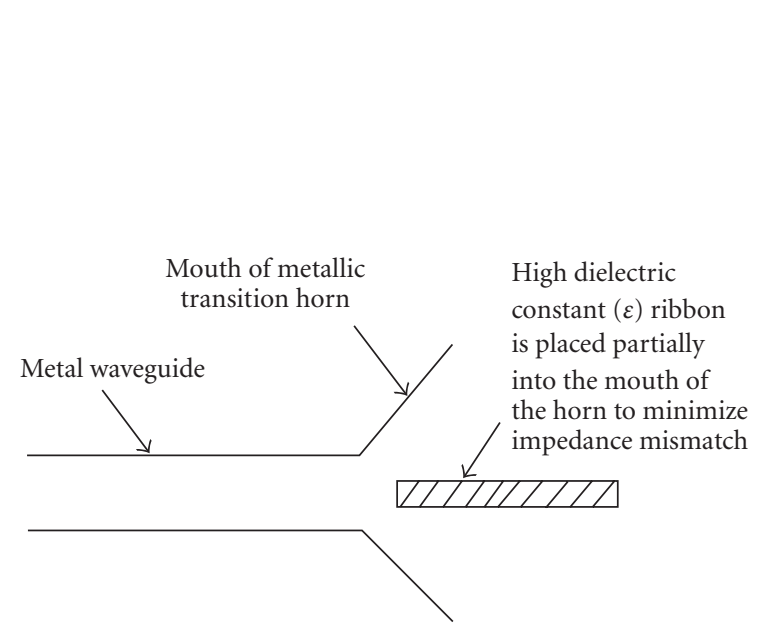

(a)

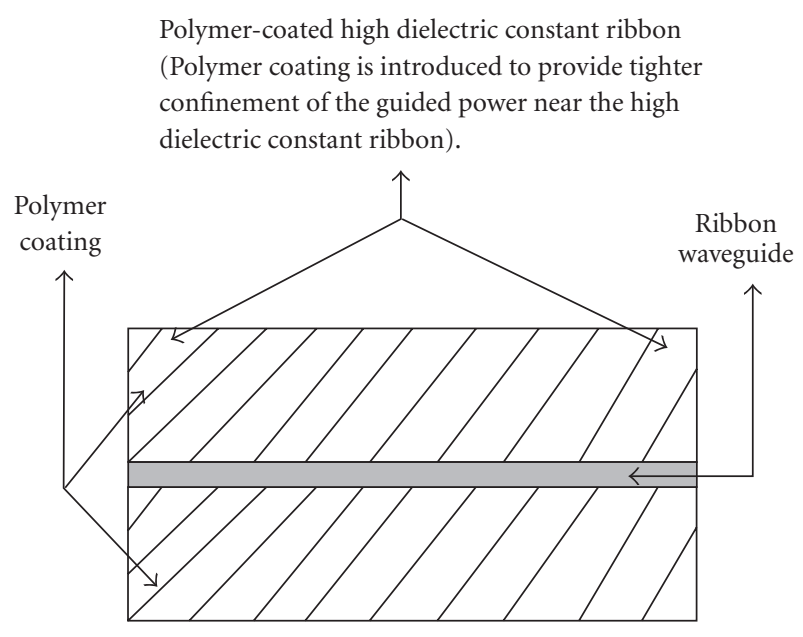

(b)

FIgURE 7: (a) Rectangular metal waveguide to high dielectric constant ribbon waveguide transition [17]. (b) Longitudinal cross-sectional geometry of a polymer-coated high dielectric constant ribbon. The thickness and the width of the high dielectric constant ribbon are $0.0635 \lambda_{0}$ and $0.635 \lambda_{0}$, respectively. The thickness of the polymer coating is approx. $0.25 \lambda_{0}$, and the width is approx. $0.635 \lambda_{0}$. The dielectric constant of the ribbon is 10 while that of the polymer is 2.04 [17].

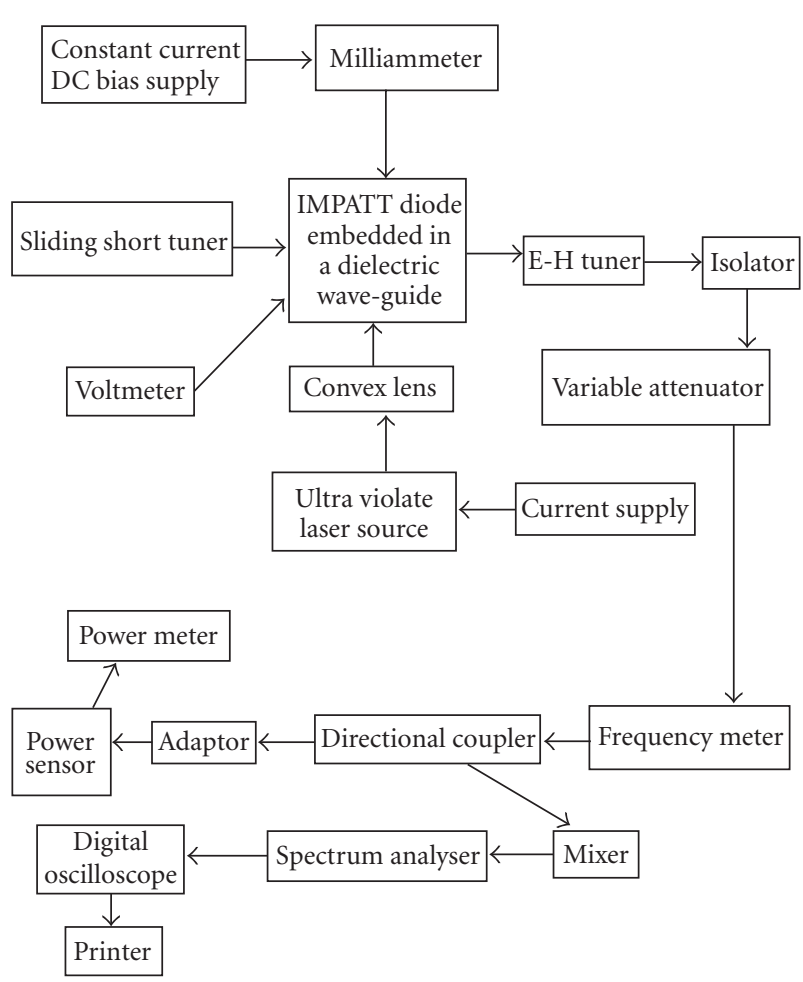

FIGURE 8: Experimental setup for optical illumination experiment on $4 \mathrm{H}-\mathrm{SiC}$ IMPATT diode at $\mathrm{THz}$ region.

through a $140 \mathrm{~mm}$ wide and $300 \mu \mathrm{m}$ thick silicon slabs may be used (see Figure 6) [18]. For higher frequency $(3 \mathrm{THz})$ power transfer, a ribbon-like structure fabricated from ceramic alumina may be utilized [17]. The schematic diagrams of the structures are shown in Figures $7(\mathrm{a})$ and $7(\mathrm{~b})$.

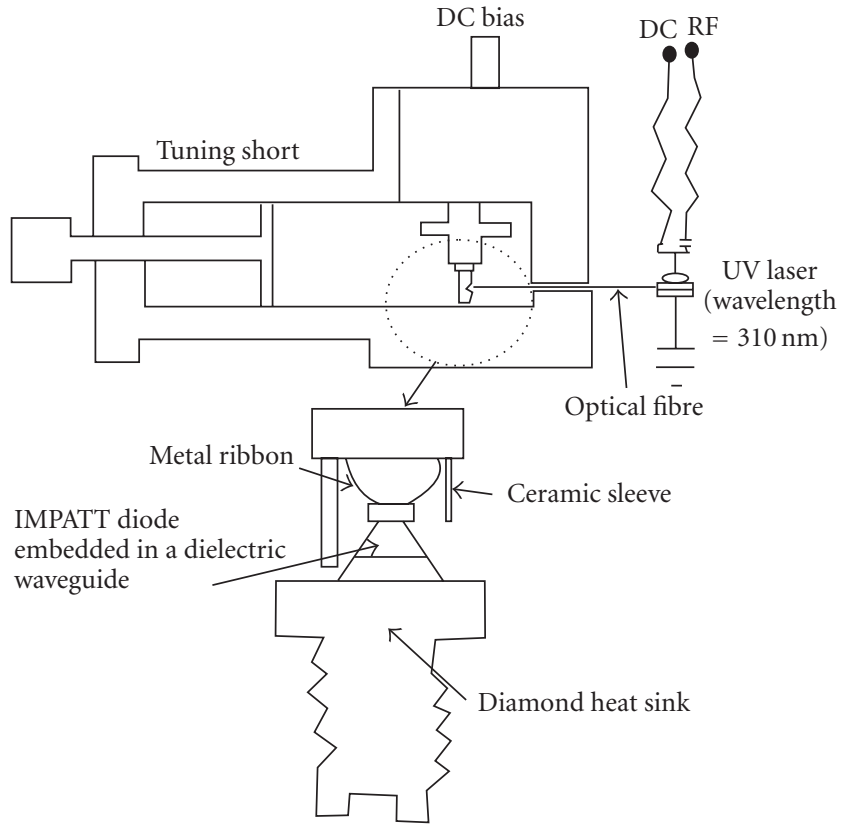

FIgURE 9: Optical experimental setup for THz IMPATT diode.

Measurements of THz power and frequency may be done with a $\mathrm{THz}$ vector network analyzer (VNA) or, by employing photoconductive method (as shown in right-hand diagram of Figure 6).

An arrangement similar to that shown in Figures 8 and 9, appropriately modified to include the photoconductive detection of $\mathrm{THz}$ power and frequency, can be used for optical illumination experiment on $4 \mathrm{H}-\mathrm{SiC}$ IMPATT. The intensity of radiation may be experimentally increased by a convex lens as indicated in Figure 8. 
It is concluded that these findings may be utilized for realizing optically integrated $\mathrm{THz}$ modules for effective applications in $\mathrm{THz}$ communication and in interstellar explorers.

\section{ACKNOWLEDGMENTS}

The authors (Moumita Mukherjee) and (Nilratan Mazumder) wish to express their gratitude to the Director, International Institute of Information Technology, Kolkata for his interest in the work. Moumita Mukherjee is grateful to Defence Research and Development Organisation (DRDO), New Delhi, India for awarding her a Senior Research Fellowship to carry out this work. Preliminary simulation results of $\mathrm{Ka}$-band $4 \mathrm{H}$-SiC IMPATT diodes were published in Proceedings of 12th Microcoll Conference on Microwave Communication, held during May 14-16 2007 in Budapest, Hungary, pp. 187-190.

\section{REFERENCES}

[1] P. H. Siegel, "Terahertz technology," IEEE Transactions on Microwave Theory and Techniques, vol. 50, no. 3, pp. 910-928, 2002.

[2] V. V. Buniatyan and V. M. Aroutiounian, "Wide gap semiconductor microwave devices," Journal of Physics D, vol. 40, no. 20, pp. 6355-6385, 2007.

[3] R. Madar, "Silicon carbide in contention," Nature, vol. 430, no. 7003, pp. 974-975, 2004.

[4] R. Yakimova and E. Janzén, "Current status and advances in the growth of SiC," Diamond and Related Materials, vol. 9, no. 3-6, pp. 432-438, 2000.

[5] M. Mukherjee, N. Mazumder, and A. Dasgupta, "Analysis of photo-illuminated millimeter wave high power IMPATT oscillator," in Proceedings of the 12th Microcoll Conference on Microwave Communication (MOW '07), pp. 187-190, Budapest, Hungary, May 2007.

[6] M. Mukherjee and N. Mazumder, "Effect of optical illumination on $4 \mathrm{H}-\mathrm{SiC}$ DDR IMPATT diodes at $140 \mathrm{GHz}$," in Proceedings of the 3rd International Conference on Computers and Devices for Communication (CODEC '06), pp. 298-301, Kolkata, India, December 2006.

[7] H. P. Vyas, R. J. Gutmann, and J. M. Borrego, "Effect of hole versus electron photocurrent on microwave-optical interactions in impatt oscillators," IEEE Transactions on Electron Devices, vol. 26, no. 3, pp. 232-234, 1979.

[8] M. B. Tagaev, "Effect of ionizing radiation on the silicon IMPATT diode characteristics," Turkish Journal of Physics, vol. 23, no. 6, pp. 985-988, 1999.

[9] S. K. Roy, M. Sridharan, R. Ghosh, and B. B. Pal, "Computer method for the dc field and carrier current profiles in the IMPATT device starting from the field extremum in the depletion layer," in Proceedings of the 1st Conference on Numerical Analysis of Semiconductor Devices (NASECODE I), J. H. Miller, Ed., pp. 266-274, Dublin, Ireland, June 1979.

[10] "Electronic Archive: New Semiconductor Materials, Characteristics and Properties," http://www.ioffe.ru/SVA/NSM/ Semicond/.SiC

[11] M. Mukherjee, N. Mazumder, S. K. Roy, and K. Goswami, "GaN IMPATT diode: a photo-sensitive high power terahertz source," Semiconductor Science and Technology, vol. 22, no. 12, pp. 1258-1267, 2007.
[12] M. G. Adlerstein, L. H. Holway Jr., and S. L. G. Chu, "Measurement of series resistance in impatt diodes," IEEE Transactions on Electron Devices, vol. 30, no. 2, pp. 179-182, 1983.

[13] H. K. Gummel and J. L. Blue, "A small signal theory of avalanche noise in IMPATT diodes," IEEE Transactions on Electron Devices, vol. 14, no. 9, pp. 569-580, 1967.

[14] M. Mukherjee and N. Mazumder, "Optically illuminated 4HSiC terahertz IMPATT device," Egyptian Journal of Solids, vol. 30, no. 1, pp. 87-102, 2007.

[15] P. Friedrichs, "Technological challenges for manufacturing power devices in SiC," in Proceedings of the CS MANTECH Conference, pp. 221-224, Austin, Tex, USA, May 2007.

[16] H. Vang, M. Lazar, P. Brosselard, et al., "Ni-Al ohmic contact to p-type 4H-SiC," Superlattices and Microstructures, vol. 40, no. 4-6, pp. 626-631, 2006.

[17] C. Yeh, F. Shimabukuro, and P. H. Siegel, "Low-loss terahertz ribbon waveguides," Applied Optics, vol. 44, no. 28, pp. 59375946, 2005.

[18] M. Wächter, M. Nagel, and H. Kurz, "Metallic slit waveguide for dispersion-free low-loss terahertz signal transmission," Applied Physics Letters, vol. 90, no. 6, Article ID 061111, 3 pages, 2007. 

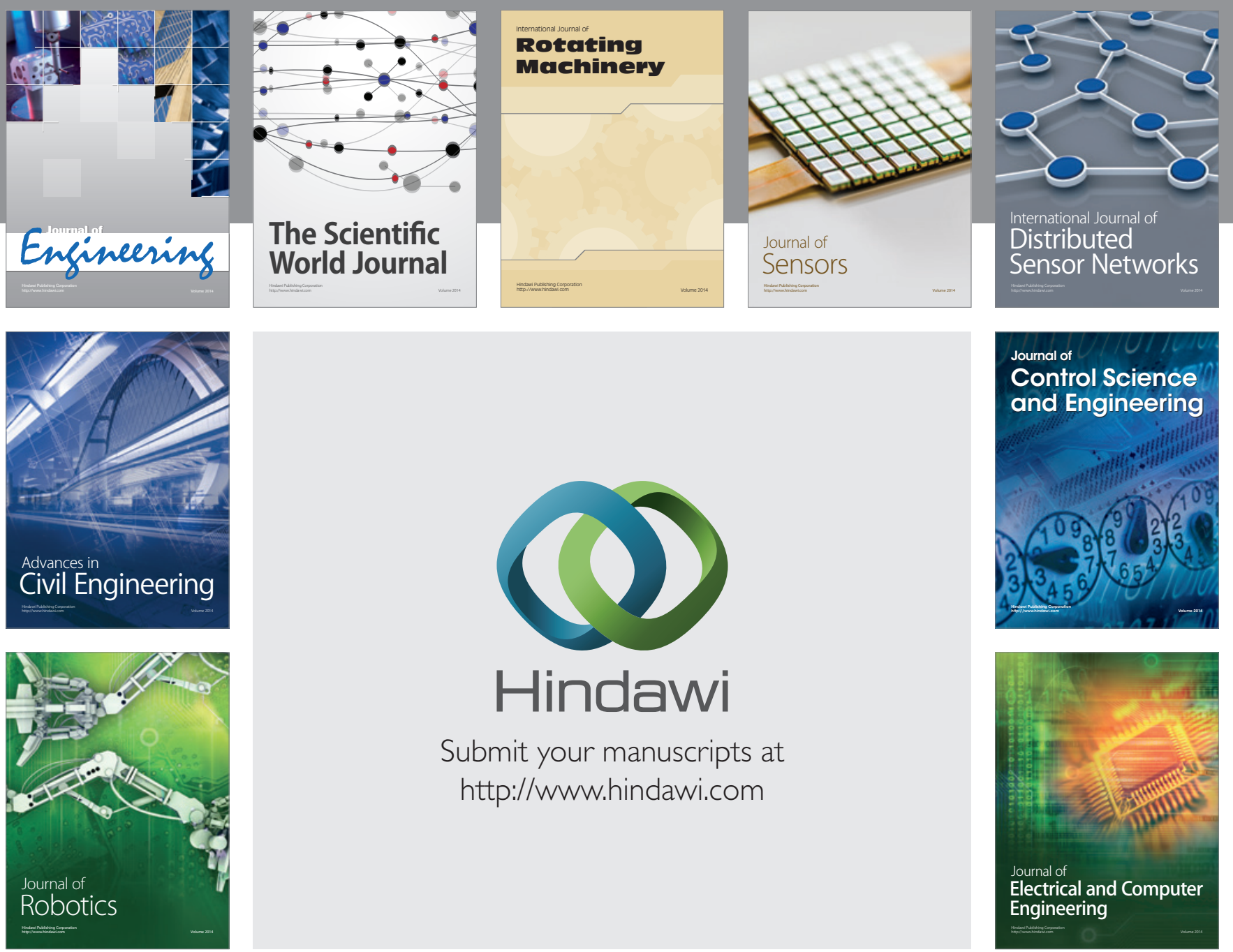

Submit your manuscripts at

http://www.hindawi.com
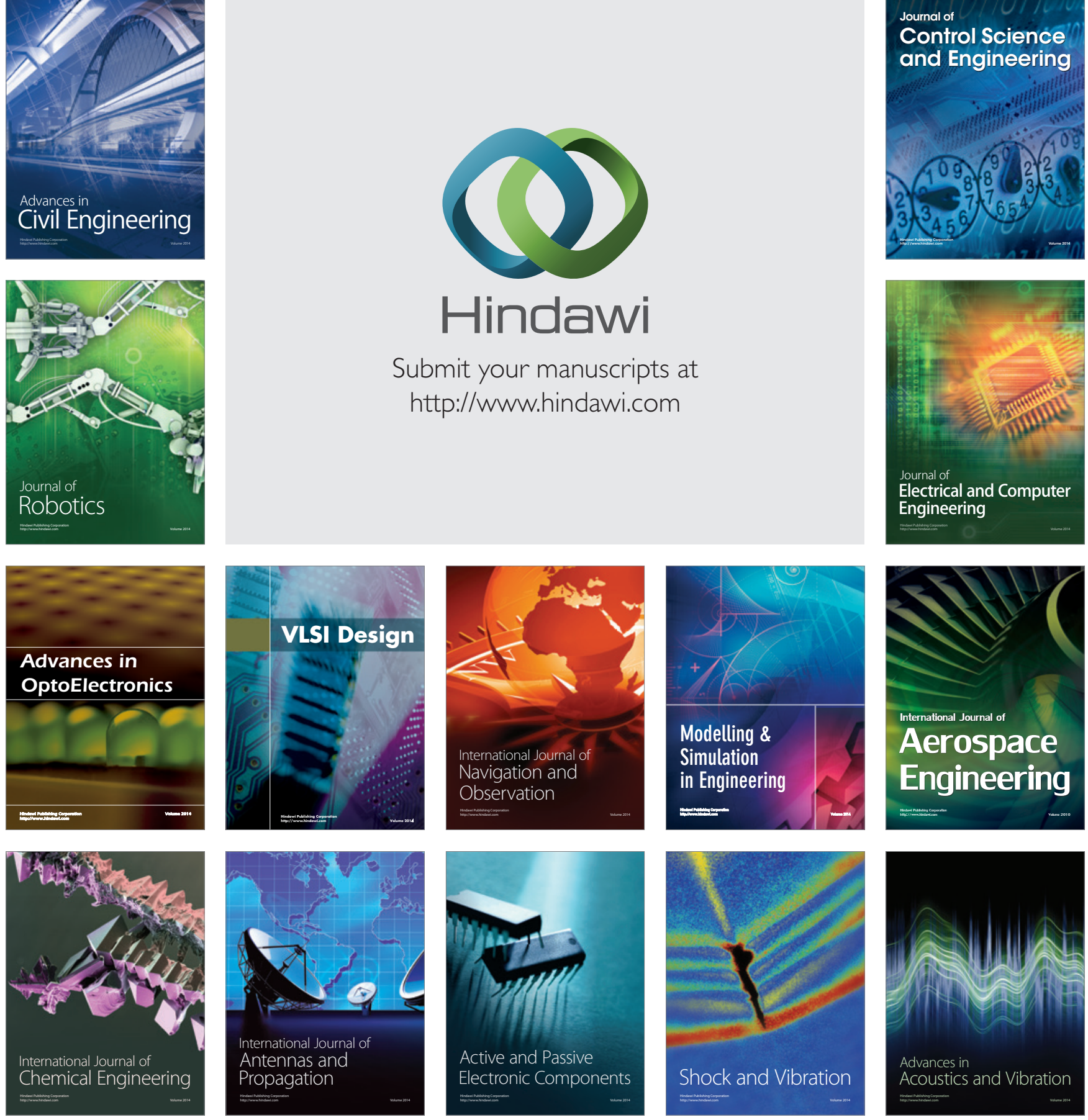